\title{
Activity of the Succinate Dehydrogenase Inhibitor Fungicide Penthiopyrad Against Sclerotinia sclerotiorum
}

\author{
Xuewei Mao, Yingfan Wang, Yiping Hou, ${ }^{\dagger}$ and Mingguo $\mathrm{Zhou}^{\dagger}$ \\ College of Plant Protection, Nanjing Agricultural University, Key Laboratory of Pesticide, Nanjing, Jiangsu Province, 210095 , \\ China
}

\begin{abstract}
In present study, the morphological and physiological characteristics of Sclerotinia sclerotiorum (Lib.) de Bary to a novel succinate dehydrogenase inhibitor (SDHI) fungicide penthiopyrad has been reported. The baseline sensitivity of S. sclerotiorum to penthiopyrad was determined using 119 strains by inhibition of mycelial growth. The median effective concentration $\left(\mathrm{EC}_{50}\right)$ values for penthiopyrad ranged from 0.0096 to $0.2606 \mu \mathrm{g} / \mathrm{ml}$, and the mean value was $0.0578( \pm 0.0626) \mu \mathrm{g} / \mathrm{ml}$. After $1 \mu \mathrm{g} / \mathrm{ml}$ penthiopyrad treatment,

acid (OA), and exopolysaccharide (EPS) content decreased markedly and mycelial respiration was distinctly inhibited. The number and dry weight of sclerotia significantly decreased after being treated with $2 \mu \mathrm{g} / \mathrm{ml}$ penthiopyrad. Penthiopyrad exhibited both protective and curative activity on the detached rapeseed leaves. Importantly, the above results will provide us more information on penthiopyrad for management of diseases caused by $S$. sclerotiorum and increase our understanding of action of penthiopyrad against $S$. sclerotiorum.
\end{abstract} mycelia of S. sclerotiorum strains showed increased apical branching and were denser compared with control, and cell membrane permeability significantly increased. In addition, glycerol content, oxalic

Keywords: Sclerotinia sclerotiorum, penthiopyrad, sensitivity distribution, activity

The filamentous ascomycete Sclerotinia sclerotiorum (Lib.) de Bary is a universal plant-pathogenic fungus that attacks more than 408 species of plants from 278 genera in 75 families, such as, oilseed rape, soybean, sugar beet, peanut and garden lettuce (Bolton et al. 2006; Derbyshire and Denton-Giles 2016; Derbyshire et al. 2017; Guyon et al. 2014; Li et al. 2017). Sclerotinia stem rot (SSR) is caused by S. sclerotiorum (Zhao et al. 2004), which can affect leaves, stems, and pods at different crop developmental stages (Liu et al. 2009; Wang et al. 2016). SSR is a serious disease of oilseed rape and results in serious losses in yield and quality of many important field and vegetable crops in many countries, such as the United States, Canada, Australia, and China (Aghajani et al. 2010; Di et al. 2016; Xu et al. 2013). In China, the incidence rate can exceed $80 \%$ in severe epidemic years (Liu et al. 2018a; Zhu et al. 2016).

Currently, management methods for control of SSR include using disease-free seed, rotating crops, frequent plowing, timing irrigation events to reduce periods of leaf wetness, and applying fungicides. However, applying different fungicides is still the dominant method for controlling SSR (Duan et al. 2012; Kurt et al. 2011; Steadman 1979; D. F. Xu et al. 2014). Since the 1980s, carbendazim (benzimidazole fungicide) has been widely applied for controlling SSR in China. Unfortunately, carbendazim-resistant strains were detected in the field in 1998 (Zhang et al. 2003). Due to the reduced efficacy of carbendazim to control SSR, the dicarboximide fungicides dimethachlon, iprodione, and procymidone have been applied for control of SSR (Wang et al. 2016), but dimethachlon-resistant strains developed and were detected in 2014 (Zhou et al. 2014a, b). Thus, it is necessary to find more

${ }^{\dagger}$ Corresponding authors: Y. P. Hou, houyiping@njau.edu.cn;

M. G. Zhou,mgzhou@njau.edu.cn

Funding: This study was sponsored by the National Key Research and Development Program of China (2018YFD0200503) and National Natural Science Foundation of China (31772191).

The author(s) declare no conflict of interest.

Accepted for publication 4 April 2020.

(C) 2020 The American Phytopathological Society effective alternative fungicides with different modes of action to reduce the risk of fungicide resistance development.

The succinate dehydrogenase inhibitor (SDHI) fungicide penthiopyrad (pyrazole carboxamide) [(R,S)-N-[2-(1,3-dimethylbutyl)thien3-yl]-1-methyl-3-trifluoromethyl-1H-pyrazole-4-carboxamide; MTF-753] is a novel fungicide; its molecular formula is $\mathrm{C}_{16} \mathrm{H}_{20} \mathrm{~F}_{3} \mathrm{~N}_{3} \mathrm{OS}$. Penthiopyrad interferes with fungal respiration in complex II of the cytochrome system and inhibits fungal respiration. As a result of this effect, the fungus cannot produce vital energy in the form of ATP (Avenot and Michailides 2010). Penthiopyrad was first commercially registered in the United States in 2012 and has shown excellent efficacy against many different plant diseases, such as rust, gray mold, apple scab, tomato leaf mold, apple blossom blight, wheat diseases, snow mold, and so on (Avenot et al. 2012; Yanase et al. 2007). Also, Proffer et al. (2013) showed that penthiopyrad had excellent potential to control cherry leaf spot (CLS) (caused by the ascomycete fungus Blumeriella jaapii) and powdery mildew (PM) (caused by Podosphaera clandestine) of tart cherry (Proffer et al. 2013). Culbreath et al. (2009) indicated that penthiopyrad had excellent efficiency for control of leaf spot (caused by Cercospora arachidicola and Cercosporidium personatum), stem rot diseases (caused by Sclerotium rolfsii), and Rhizoctonia limb rot (caused by Rhizoctonia solani) of peanut (Culbreath et al. 2009). In addition, the fungicidal activity of penthiopyrad against spore germination, sporulation, and inhibiting mycelium elongation of Botrytis cinerea has been reported (Yanase et al. 2007).

Up to now, penthiopyrad has not been registered to manage SSR. As we know, during the registration process in the European Union, establishment of baseline sensitivity is essential when introducing a fungicide to control a plant pathogen (Russell 2004). Penthiopyrad may be a new potential alternative fungicide for controlling SSR. The effects of penthiopyrad on S. sclerotiorum in vitro have not been reported. Therefore, the objectives of this study were to (i) establish the baseline sensitivity to penthiopyrad in $S$. sclerotiorum strains by mycelial growth rate method, (ii) assay the effect of penthiopyrad on morphological and physiological characteristics of S. sclerotiorum, and (iii) test the protective and curative activity of penthiopyrad for controlling SSR on leaves of rapeseed. This will provide new reference for controlling SSR and further increase our understanding about the mode of action of penthiopyrad and provide experimental evidence for controlling $S$. sclerotiorum in future. 


\section{Materials and Methods}

Media and fungicides. Potato dextrose agar (PDA): $200 \mathrm{~g}$ of fresh potato tuber, $15 \mathrm{~g}$ of agar, and $20 \mathrm{~g}$ of dextrose per liter of distilled water. YEPD liquid medium was made from $3 \mathrm{~g}$ yeast extract, $10 \mathrm{~g}$ peptone, and $20 \mathrm{~g}$ dextrose per liter of distilled water.

Penthiopyrad (active ingredient 99.9\%) was provided by Mitsui Chemicals Inc. Penthiopyrad was dissolved in methanol to obtain $10,000 \mu \mathrm{g} / \mathrm{ml}$ stock solution and was diluted to a series of concentrations of $4,000,1,000,250,62.5,15.625$, and $3.9 \mu \mathrm{g} / \mathrm{ml}$ with methanol.

Isolation of $S$. sclerotiorum. A total 119 isolates of S. sclerotiorum were obtained from 10 different oilseed rape fields in Jiangsu Province, China, in 2017 and 2018. In each field, three to five single sclerotia of SSR were randomly collected and air-dried. The surface of each sclerotia was immersed in $1 \% \mathrm{NaClO}$ solution for $2 \mathrm{~min}$. Then, they were rinsed thrice in sterile distilled water and air-dried. The sclerotia were placed in PDA plates amended with $100 \mu \mathrm{g} / \mathrm{ml}$ streptomycin sulfate for 4 days at $25^{\circ} \mathrm{C}$ in the dark. Eventually, a single sclerotium was transferred to a PDA slant followed by storage at $4^{\circ} \mathrm{C}$ (Stammler et al. 2007). Penthiopyrad had never been used to control SSR of oilseed rape in diseased plants before collection.

Baseline sensitivity of mycelial growth of $S$. sclerotiorum populations to penthiopyrad. In order to evaluate the activity of penthiopyrad on mycelial growth of $S$. sclerotiorum populations, the baseline sensitivity of mycelial growth of $S$. sclerotiorum populations to penthiopyrad was set up by analyzing the distribution of median effective concentration $\left(\mathrm{EC}_{50}\right)$ values of 119 isolates from different regions. Briefly, mycelial plugs $(5 \mathrm{~mm}$ diameter) were cut from the margin of each colony that had been cultured for 2 days at $25^{\circ} \mathrm{C}$, and the plugs were transferred to PDA plates containing $0,0.0039,0.015625,0.0625,0.25,1$, and $4 \mu \mathrm{g} / \mathrm{ml}$ penthiopyrad. Each concentration had three replications. Plates without penthiopyrad were prepared as the control. All PDA plates were cultured at $25^{\circ} \mathrm{C}$ for 2 days in darkness, and then the mean diameter of the colony was determined. $\mathrm{EC}_{50}$ was calculated based on linear regression of colony diameter on $\log 10$-transformed fungicide concentration (Liu et al. 2017, 2018b).

Effect of penthiopyrad on mycelial morphology of S. sclerotiorum. Three strains of S. sclerotiorum TZ51S, TZ84S, and TZ55S were used for mycelial morphology study. Briefly, mycelium of TZ51S, TZ84S, and TZ55S from the edge of 2-day-old colonies were put onto sterilized slides containing $1 \mathrm{ml}$ PDA medium amended with $1 \mu \mathrm{g} / \mathrm{ml}$ penthiopyrad. Slides without penthiopyrad were used as the control. After $12 \mathrm{~h}$ culturing at $25^{\circ} \mathrm{C}$ in darkness, the morphology of the top of each strain was observed by light microscope (Olympus IX-71, Japan). There were three replications in the experiment and the experiment was repeated twice.

Effect of penthiopyrad on sclerotial production of S. sclerotiorum. Five strains of $S$. sclerotiorum SA42S, SY7S, TZ51S, TZ84S, and TZ55S were chosen randomly for a sclerotial production assay. Mycelial plugs ( $5 \mathrm{~mm}$ diameter) from the margin of a 2-day-old colony were transferred to PDA plates amended with $0.125,0.25,0.5,1$, and $2 \mu \mathrm{g} / \mathrm{ml}$ penthiopyrad. Plates without penthiopyrad were prepared as the control. All plates were incubated at $25^{\circ} \mathrm{C}$ for 1 month with three replicates. The number and the dry weight of the sclerotia formed on each plate was assessed. The experiment was performed three times.

Effect of penthiopyrad on cell membrane permeability of S. sclerotiorum. Three strains of TZ51S, TZ84S, and TZ55S were chosen for this experiment. Mycelial plugs (5 $\mathrm{mm}$ diameter) were

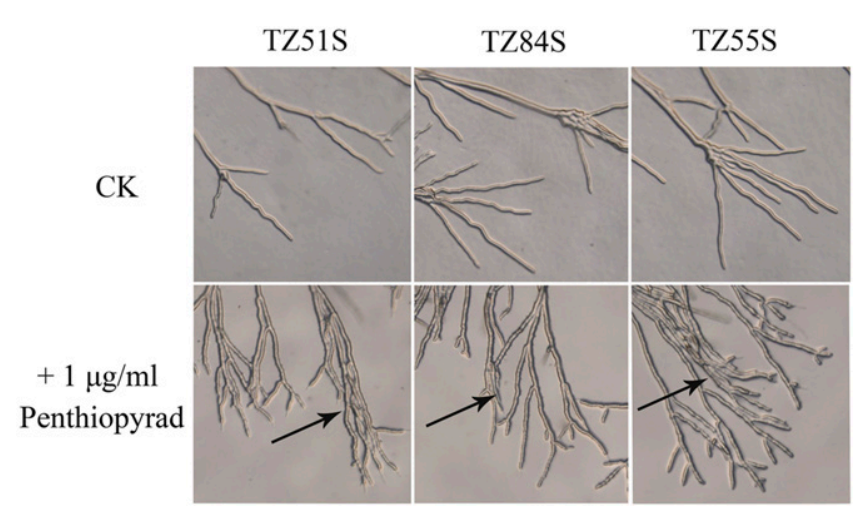

Fig. 2. Effect of $1 \mu \mathrm{g} / \mathrm{ml}$ penthiopyrad on Sclerotinia sclerotiorum strains (TZ51S, TZ84S, and TZ55S).

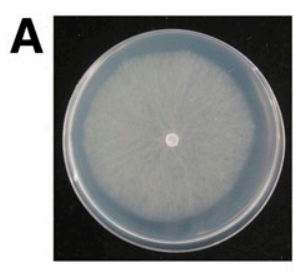

$0 \mu \mathrm{g} / \mathrm{ml}$

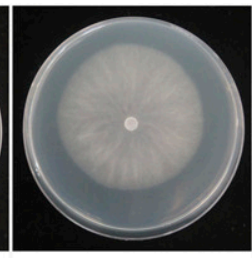

$0.0039 \mu \mathrm{g} / \mathrm{ml}$

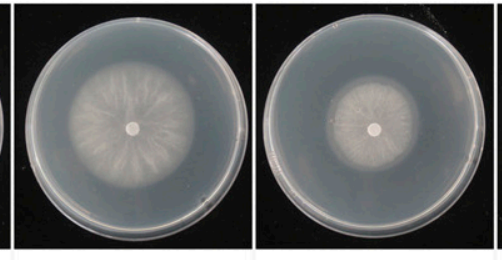

$0.015625 \mu \mathrm{g} / \mathrm{ml}$

$0.0625 \mu \mathrm{g} / \mathrm{ml}$

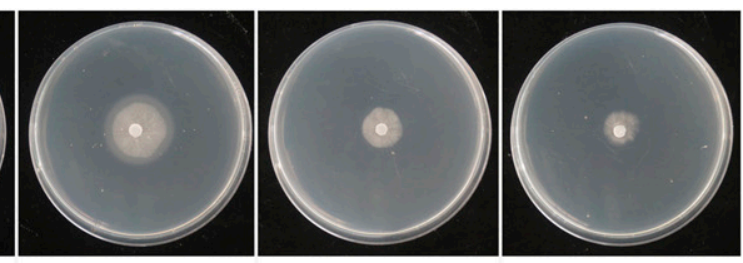

$0.25 \mu \mathrm{g} / \mathrm{ml}$

$1 \mu \mathrm{g} / \mathrm{ml}$

$4 \mu \mathrm{g} / \mathrm{ml}$

B

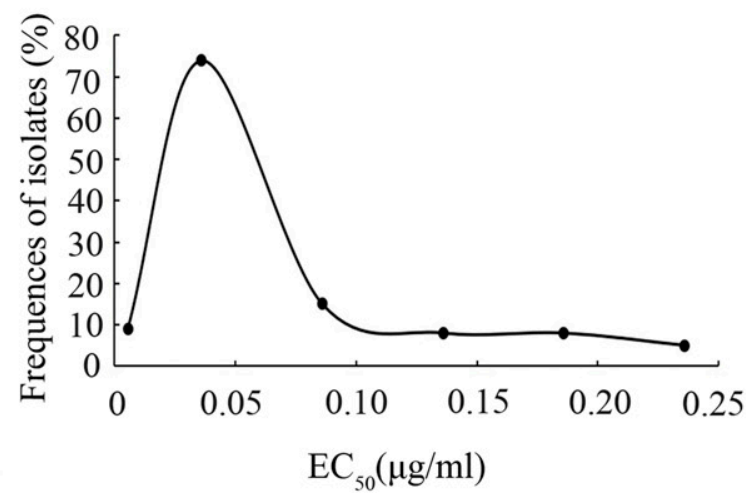

Fig. 1. The effect of penthiopyrad on Sclerotinia sclerotiorum. A, The inhibition effect of penthiopyrad against TZ84S of S. sclerotiorum in different concentrations of penthiopyrad. B, Distribution of penthiopyrad $\mathrm{EC}_{50}$ values for 119 isolates of $S$. sclerotiorum by inhibition of mycelial growth. 
cut from the margin of fresh, actively growing colonies that had been cultured for 2 days. The plugs were added to $250 \mathrm{ml}$ triangular flasks containing $100 \mathrm{ml}$ YEPD liquid medium and the triangular flasks were shaken at $25^{\circ} \mathrm{C}, 175 \mathrm{rpm}$ in a rotary shaker for $36 \mathrm{~h}$. After 36 $\mathrm{h}$, partial triangular flasks were amended with penthiopyrad to a final concentration of $1 \mu \mathrm{g} / \mathrm{ml}$, all the strains were shaken for additional 36 $\mathrm{h}$, and $0.3 \mathrm{~g}$ of hyphae were collected through three pieces of lens wiping paper and washed thrice with double distilled water and suspended in $20 \mathrm{ml}$ of double distilled water. Conductivity of the distilled water was measured after $0,5,10,20,40,60,80,100,120$, 140,160 , and $180 \mathrm{~min}$ with a conductivity meter (CON510 Eutech/Oakton, Singapore) to assess the extent of leaching of cell contents through cell membranes. After $3 \mathrm{~h}$, the mycelia were boiled for an additional $5 \mathrm{~min}$ to measure the final conductivity. The relative conductivity of mycelia was calculated as: relative conductivity (\%) $=$ conductivity $/$ final conductivity $\times 100$. There were three replicates for each treatment and the experiment was repeated three times.

Glycerol content of mycelia. Three strains of TZ51S, TZ84S, and TZ55S were chosen for this experiment, and glycerol content was determined by the cupric glycerinate colorimetry method (Yan and Qiu 2004). A standard curve for glycerol content was established as follows: $10 \mathrm{ml}$ different concentration of glycerol solution $(0$, $0.0003125,0.000625,0.00125,0.0025$, and $0.005 \mathrm{~g} / \mathrm{ml})$ were added to 50 - $\mathrm{ml}$ centrifuge tubes; $1 \mathrm{ml}$ of $\mathrm{CuSO}_{4}$ solution $(0.05 \mathrm{~g} / \mathrm{ml})$ and $3.5 \mathrm{ml}$ of $\mathrm{NaOH}$ solution $(0.05 \mathrm{~g} / \mathrm{ml})$ were then added. The centrifuge tubes were placed on a rotary shaker $(100 \mathrm{rpm})$ for $12 \mathrm{~min}$ and the solution was filtered through sterilized lens paper. Absorbance was measured at $630 \mathrm{~nm}$ with a microplate (VersaMax, Molecular Devices, San Jose, CA, U.S.A.). The standard curve was drawn according to the absorbance value.

Mycelial plugs ( $5 \mathrm{~mm}$ diameter) were cut from the margin of fresh, actively growing colonies that had been cultured for 2 days. The plugs were added to $250 \mathrm{ml}$ triangular flasks containing $100 \mathrm{ml}$ YEPD liquid medium and the triangular flasks were shaken at $25^{\circ} \mathrm{C}, 175 \mathrm{rpm}$ in a rotary shaker for $36 \mathrm{~h}$. After $36 \mathrm{~h}$, the triangular flasks were amended with penthiopyrad to a final concentration of $1 \mu \mathrm{g} / \mathrm{ml}$ and shaken for an additional $36 \mathrm{~h}$. The mycelia powder $(0.5 \mathrm{~g})$ of each sample was transferred to $20 \mathrm{ml}$ of sterile distilled water $\left(50 \mathrm{ml}\right.$ centrifuge tube) and heated at $80^{\circ} \mathrm{C}$ for $15 \mathrm{~min}$. Then the tube was centrifuged at $8,000 \mathrm{rpm}$ for $10 \mathrm{~min}$. After centrifugation, the supernatant was used for glycerol content assay. The glycerol concentration of each sample in the supernatants was determined with the standard curve. There were three replicates for each sample, and the experiment was performed three times.

Oxalic acid content. Oxalic acid (OA) content was measured according to methods described in previous studies with some modification (Duan et al. 2007, 2013; Wang et al. 2016). The standard curve was established by previous study (Duan et al. 2007, 2013). Three strains of TZ51S, TZ84S, and TZ55S were chosen for this experiment. Mycelial plugs ( $5 \mathrm{~mm}$ diameter) cut from the margins of actively growing colonies that had been cultured for 2 days on PDA were transferred to $250 \mathrm{ml}$ flasks containing $100 \mathrm{ml}$ YEPD liquid medium treated with penthiopyrad at the concentration of $1 \mu \mathrm{g} / \mathrm{ml}$. Flasks without penthiopyrad were used as control. After the flasks were shaken on a rotary shaker $(175 \mathrm{rpm})$ at $25^{\circ} \mathrm{C}$ for 4 days, the contents were centrifuged at 1,500 rpm for $10 \mathrm{~min}$. Finally, the absorbance values of the OA content in the supernatants were measured at $510 \mathrm{~nm}$ using a microplate reader (VersaMax, Molecular Devices); OA content was determined according to the standard curve. There were three flasks per treatment and the experiment was repeated three times.

Effect of penthiopyrad on exopolysaccharides (EPS) content of S. sclerotiorum. The quantity of EPS produced by S. sclerotiorum was determined by a modified version of the phenol-sulfuric acid method (DuBois et al. 1956; Rao and Pattabiraman 1989). For preparation of an EPS standard curve, $2 \mathrm{ml}$ of a glucose solution $(0,20$, $40,60,80,100,120,160$, and $200 \mu \mathrm{g} / \mathrm{ml}), 1 \mathrm{ml}$ of $5 \%$ phenol solution, and $5 \mathrm{ml}$ of concentrated $\mathrm{H}_{2} \mathrm{SO}_{4}$, added slowly down the side of the test tube, were mixed, then vortexed for $10 \mathrm{~s}$, and incubated for $30 \mathrm{~min}$ at $25^{\circ} \mathrm{C}$. Absorbance of the mixture solution was detected at $490 \mathrm{~nm}$ by a microplate reader and a standard curve was established by plotting absorbance against glucose concentration.

Three isolates TZ51S, TZ84S, and TZ55S of S. sclerotiorum were selected randomly for the EPS assay. Five mycelial plugs $(5 \mathrm{~mm}$ in diameter) taken from 2-day-old colonies of each isolate were transferred to $250 \mathrm{ml}$ flasks containing $100 \mathrm{ml}$ of YEPD. After the flasks were shaken on a rotary shaker $\left(175 \mathrm{rpm}, 25^{\circ} \mathrm{C}\right)$ for $36 \mathrm{~h}$, penthiopyrad was added to the flasks to a concentration of $1 \mu \mathrm{g} / \mathrm{ml}$. Then the flasks were shaken for additional $36 \mathrm{~h}$, and the supernatants were collected. EPS was precipitated from $1 \mathrm{ml}$ of each supernatant with three volumes of absolute ethanol and air dried. The EPS was dissolved in $8 \mathrm{ml}$ of distilled water; EPS content was determined according to the standard curve. There were three flasks per treatment and the experiment was repeated three times.

Inhibition of mycelial respiration. Oxygen concentration was measured with an oxygraph system (F12-ED, Julabo, China). Three strains of TZ51S, TZ84S, and TZ55S were used for mycelial respiration assay. Mycelial plugs ( $5 \mathrm{~mm}$ diameter) of $S$. sclerotiorum from 2-day-old colony margins were transferred to conical flasks containing $100 \mathrm{ml}$ YEPD for shake culture $\left(25^{\circ} \mathrm{C}, 175 \mathrm{r} / \mathrm{min}\right)$. After $36 \mathrm{~h}$, flasks were added with penthiopyrad at the ultimate concentration of 0.5 or $1 \mu \mathrm{g} / \mathrm{ml}$ and the flasks were shaken for additional $2 \mathrm{~h}$. Flasks without penthiopyrad were used as control. Then, $20 \mathrm{mg}$ mycelia were washed twice with distilled water and suspended in $2 \mathrm{ml}$ phosphate buffer $(0.15 \mathrm{M}, \mathrm{pH} 6.4$, containing $0.1 \mathrm{M}$ glucose) (Chen et al. 2009; Shirane et al. 1995). Each treatment and control were repeated six times. The suspension solution was then transferred to a measuring instrument and the inhibition of respiration was calculated using the following formula: Inhibition of respiration $(\%)=($ Oxygen consumption rate in control - Oxygen consumption in treatment)/ Oxygen consumption rate in control $\times 100$. The experiment was repeated three times.

Protective and curative activity of penthiopyrad against $S$. sclerotiorum on leaves of rapeseed. In order to understand

Table 1. Effect of penthiopyrad on sclerotial production of Sclerotinia sclerotiorum

\begin{tabular}{|c|c|c|c|c|c|c|c|c|c|c|}
\hline \multirow[b]{3}{*}{$\begin{array}{l}\text { Concentration of } \\
\text { fluazinam }(\mu \mathrm{g} / \mathrm{ml})\end{array}$} & \multicolumn{10}{|c|}{ Strains } \\
\hline & \multicolumn{2}{|c|}{ SA42S } & \multicolumn{2}{|c|}{ TZ51S } & \multicolumn{2}{|c|}{ TZ84S } & \multicolumn{2}{|c|}{ TZ55S } & \multicolumn{2}{|c|}{ SY7S } \\
\hline & $\begin{array}{l}\text { Number } \\
\text { per plate }\end{array}$ & $\begin{array}{c}\text { Dry } \\
\text { weight }(\mathrm{g})\end{array}$ & $\begin{array}{l}\text { Number } \\
\text { per plate }\end{array}$ & $\begin{array}{c}\text { Dry } \\
\text { weight }(\mathrm{g})\end{array}$ & $\begin{array}{l}\text { Number } \\
\text { per plate }\end{array}$ & $\begin{array}{c}\text { Dry } \\
\text { weight }(\mathrm{g})\end{array}$ & $\begin{array}{l}\text { Number } \\
\text { per plate }\end{array}$ & $\begin{array}{c}\text { Dry } \\
\text { weight }(\mathrm{g})\end{array}$ & $\begin{array}{l}\text { Number } \\
\text { per plate }\end{array}$ & $\begin{array}{c}\text { Dry } \\
\text { weight }(g)\end{array}$ \\
\hline 0 & $18 \mathrm{a}^{\mathrm{z}}$ & $0.402 \mathrm{a}$ & $18 \mathrm{a}$ & $0.343 \mathrm{a}$ & $20 a$ & $0.394 \mathrm{a}$ & $22 \mathrm{a}$ & $0.354 \mathrm{a}$ & $21 \mathrm{a}$ & $0.585 \mathrm{a}$ \\
\hline 0.125 & $17 \mathrm{a}$ & $0.402 \mathrm{a}$ & $15 \mathrm{ab}$ & $0.336 \mathrm{a}$ & $15 \mathrm{~b}$ & $0.368 \mathrm{ab}$ & $14 \mathrm{~b}$ & $0.292 \mathrm{ab}$ & $21 \mathrm{a}$ & $0.431 \mathrm{~b}$ \\
\hline 0.25 & $13 \mathrm{~b}$ & $0.351 \mathrm{ab}$ & $13 \mathrm{abc}$ & $0.341 \mathrm{ab}$ & $11 \mathrm{c}$ & $0.291 \mathrm{bc}$ & $13 \mathrm{~b}$ & $0.278 \mathrm{ab}$ & $21 \mathrm{a}$ & $0.376 \mathrm{c}$ \\
\hline 0.5 & $13 \mathrm{~b}$ & $0.369 \mathrm{ab}$ & $10 \mathrm{bc}$ & $0.287 \mathrm{abc}$ & $10 \mathrm{c}$ & $0.274 \mathrm{c}$ & $13 \mathrm{~b}$ & $0.242 \mathrm{~b}$ & $16 \mathrm{~b}$ & $0.343 \mathrm{c}$ \\
\hline 1 & $13 \mathrm{~b}$ & $0.318 \mathrm{ab}$ & $10 \mathrm{bc}$ & $0.270 \mathrm{bc}$ & $6 \mathrm{~d}$ & $0.254 \mathrm{c}$ & $12 \mathrm{~b}$ & $0.228 \mathrm{~b}$ & $13 \mathrm{c}$ & $0.206 \mathrm{~d}$ \\
\hline 2 & $10 \mathrm{c}$ & $0.285 \mathrm{~b}$ & $9 \mathrm{c}$ & $0.254 \mathrm{c}$ & $6 \mathrm{~d}$ & $0.250 \mathrm{c}$ & $11 \mathrm{~b}$ & $0.214 \mathrm{~b}$ & $10 \mathrm{~d}$ & $0.180 \mathrm{~d}$ \\
\hline
\end{tabular}

${ }^{\mathrm{z}}$ Means in a column followed by the same letter were not significantly different according to Fisher's least significant difference (LSD) test $(P=0.05)$. 
protective and curative activity of penthiopyrad against $S$. sclerotiorum on leaves of rapeseed, the strain TZ51S was chosen for this test. The stock solution of penthiopyrad was diluted with water containing $0.1 \%$ Tween 80 to $0,12.5,25,50,80$, and $100 \mu \mathrm{g} / \mathrm{ml}$. For protective activity assay, fully expanded leaves cut from healthy oilseed rape plants (Ning you 3) at similar growth stages were rinsed with sterile distilled water and air dried. Leaves of oilseed rape were wounded with a sterilized needle (avoiding the midrib) and sprayed with water containing $0.1 \%$ Tween 80 or different concentrations of penthiopyrad until liquid flowed on the leaf surface. After $24 \mathrm{~h}$, mycelial plugs (5 mm diameter) of $S$. sclerotiorum strain TZ51S from 2-day-old colony margins were put into leaves of rapeseed for additional $48 \mathrm{~h}$. Inoculated leaves were placed at $25^{\circ} \mathrm{C}$ with a $16 \mathrm{~h}$ photoperiod and $80 \%$ relative humidity for disease development. After incubation for $48 \mathrm{~h}$, the average lesion diameter was determined by measuring each lesion in two perpendicular directions. For the curative activity assay, leaves of oilseed rape were wounded with a sterilized needle (avoiding the midrib) and mycelial plugs $(5 \mathrm{~mm}$ diameter) of S. sclerotiorum strain TZ51S from 2-day-old colony margins were put into leaves of rapeseed for $24 \mathrm{~h}$. After $24 \mathrm{~h}$ of culturing, different concentrations of penthiopyrad above were sprayed on the leaves until liquid flowed on the leaf surface. Leaves were incubated for an additional $24 \mathrm{~h}$ at $25^{\circ} \mathrm{C}$ with a $16 \mathrm{~h}$ photoperiod and $80 \%$ relative humidity for disease development. Finally, the average lesion diameter was determined, and disease control efficacy was calculated as follows: disease control efficacy $(\%)=($ lesion diameter in the water control - lesion diameter in the treatment)/lesion diameter in the water control $\times 100$ (Kuang et al. 2011).

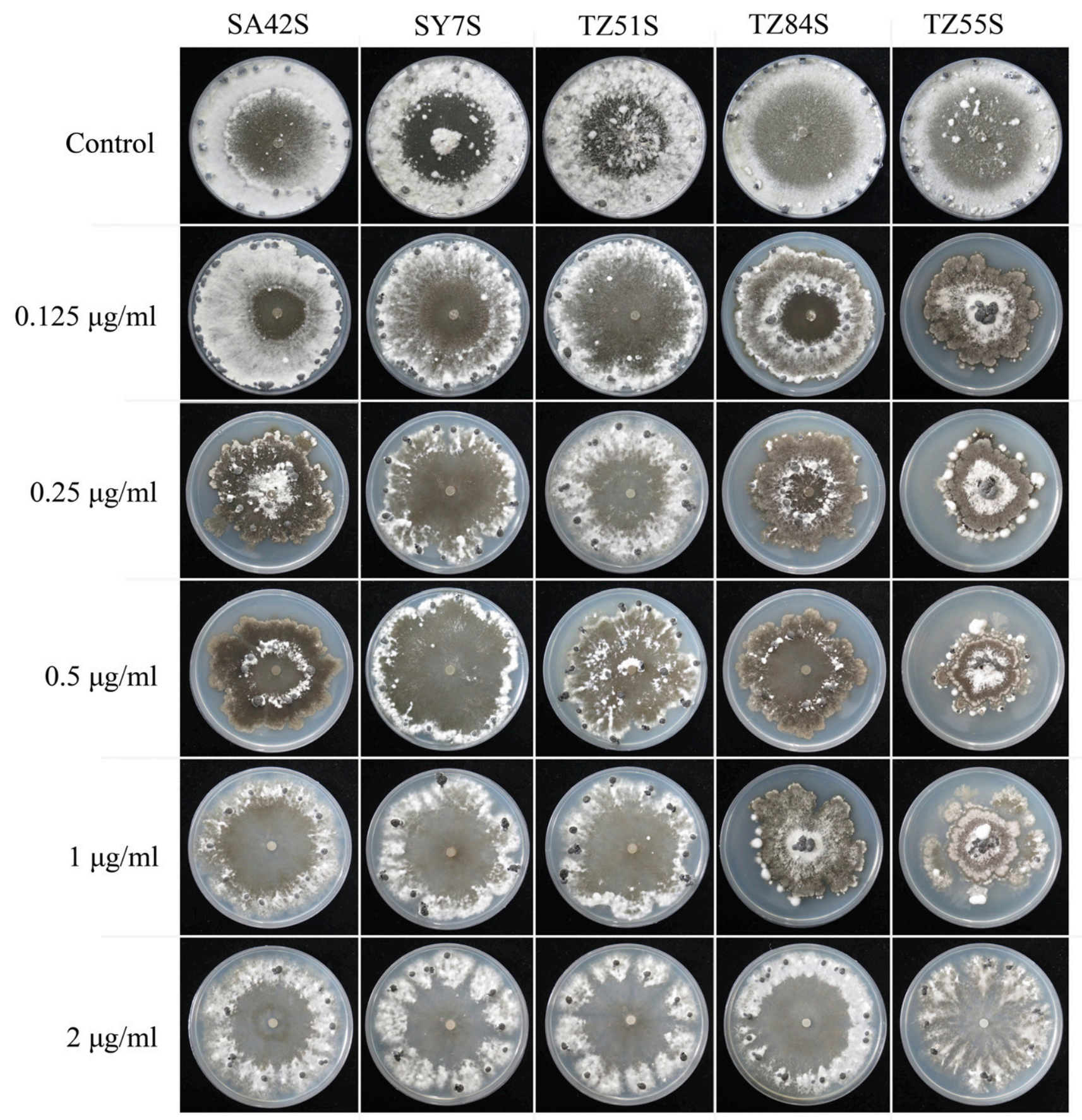

Fig. 3. Effect of different concentrations of penthiopyrad $(0.125,0.25,0.5,1$, and $2 \mu \mathrm{g} / \mathrm{ml})$ on sclerotial development of five wild-type Sclerotinia sclerotiorum strains (SA42S, SY7S, TZ51S, TZ84S, and TZ55S). 
Data analysis. All the data in the study were analyzed with the software of SPSS 14.0 (SPSS Inc. Chicago, IL) for statistical variances between repeated experiments. Data from the other experiments
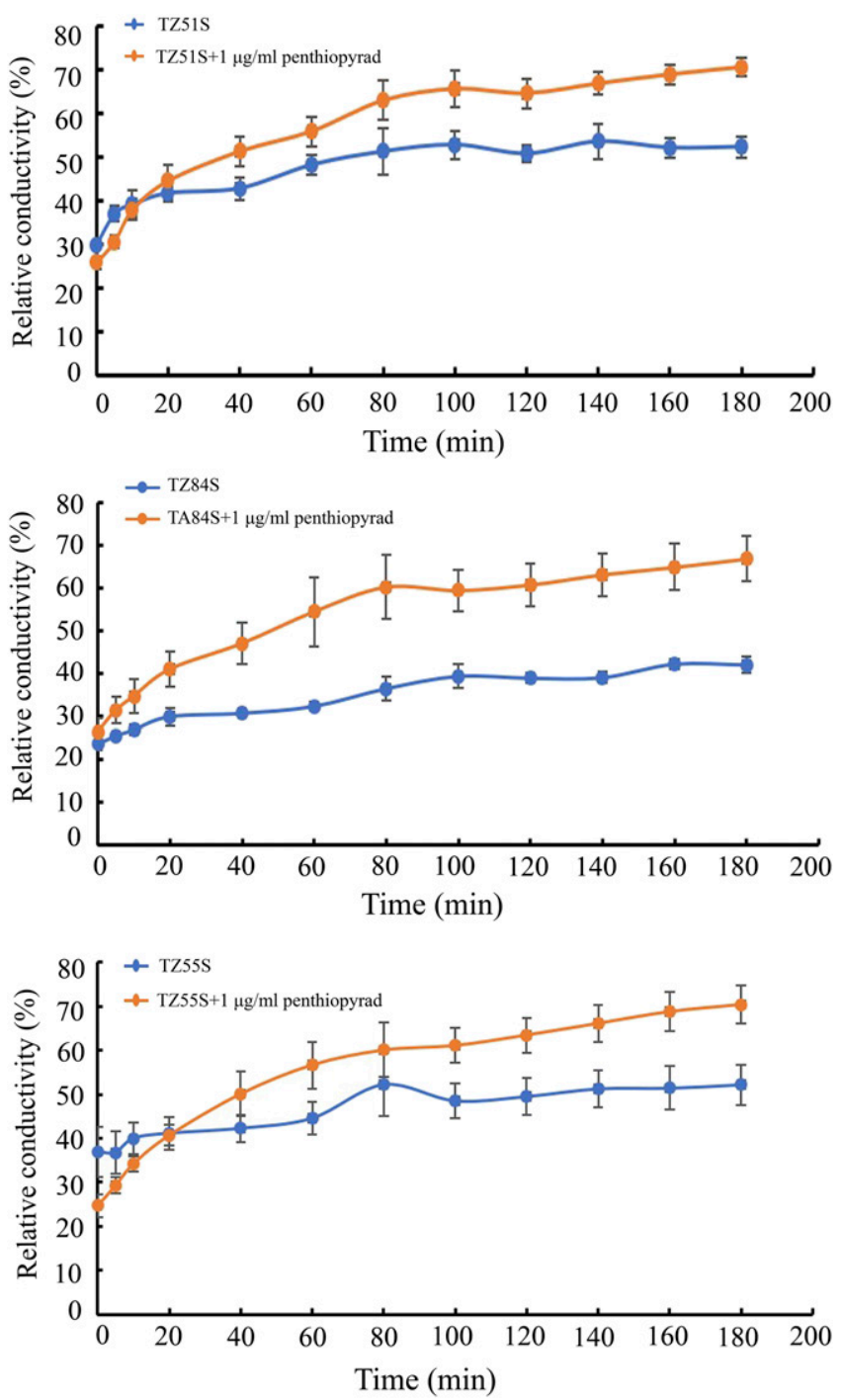

Fig. 4. Effect of $1 \mu \mathrm{g} / \mathrm{ml}$ penthiopyrad on relative conductivity of mycelia of Sclerotinia sclerotiorum strains (TZ51S, TZ84S, and TZ55S). Bars denote the standard deviation of three experiments. were analyzed using analysis of variance (ANOVA). Fisher's LSD test $(P=0.05)$ determined whether there were significant differences among the biological characteristics.

\section{Results}

In vitro baseline sensitivity of $S$. sclerotiorum to penthiopyrad. Mycelial growth of TZ84S in the presence of $0.0039,0.015625$, $0.0625,0.25,1$, and $4 \mu \mathrm{g} / \mathrm{ml}$ penthiopyrad was inhibited in a dosedependent manner (Fig. 1A). A total of 119 S. sclerotiorum field isolates that had not been previously exposed to penthiopyrad were tested on PDA plates for baseline sensitivity to penthiopyrad by mycelium growth rate method. The $\mathrm{EC}_{50}$ values for penthiopyrad ranged from 0.0096 to $0.2606 \mu \mathrm{g} / \mathrm{ml}$, and the mean value was 0.0578 $( \pm 0.0626) \mu \mathrm{g} / \mathrm{ml}$. The baseline sensitivity curve was unimodal over a sensitive range (Fig. 1B) and the range of variation factor was 27.15 (the maximum $\mathrm{EC}_{50}$ value/the minimum $\mathrm{EC}_{50}$ value). The results suggested that the fungicide penthiopyrad had a strong inhibition effect on mycelial growth of S. sclerotiorum.

Effect of penthiopyrad on mycelial morphology of $S$. sclerotiorum. After treatment with $1 \mu \mathrm{g} / \mathrm{ml}$ penthiopyrad, mycelia of $S$. sclerotiorum isolates TZ51S, TZ84S, and TZ55S showed increased apical branching and were denser compared with control (Fig. 2).

Effect of penthiopyrad on sclerotial production of $S$. sclerotiorum. When treated with $0.125 \mu \mathrm{g} / \mathrm{ml}$ and $0.25 \mu \mathrm{g} / \mathrm{ml}$ penthiopyrad, the number of sclerotia of the strains TZ84S and TZ55S decreased significantly; the strains SA42S, TZ51S, and SY7S did not change significantly compared with control (Table 1 ). Treated with $0.125,0.25,0.5$, and $1 \mu \mathrm{g} / \mathrm{ml}$ penthiopyrad, the dry weight of sclerotia of the strains SA42S, SY7S, TZ51S, TZ84S, and TZ55S did not change significantly (Table 1 ). Treated with $2 \mu \mathrm{g} / \mathrm{ml}$ penthiopyrad, the number and dry weight of sclerotia of the strains SA42S, SY7S, TZ51S, TZ84S, and TZ55S significantly decreased (Table 1, Fig. 3).

Cell membrane permeability of $S$. sclerotiorum. When treated with penthiopyrad, the cell membrane permeability of S. sclerotiorum strains TZ51S, TZ84S, and TZ55S were higher than the control (Fig. 4). The result suggested that penthiopyrad could lead to cell membrane damage and increase mycelial electrolyte leakage of $S$. sclerotiorum.

Glycerol content. The content of glycerol was determined by absorbance at $630 \mathrm{~nm}$ of inoculated YEPD treated or untreated with penthiopyrad and calculated using the standard curves (Fig. 5A). After $1 \mu \mathrm{g} / \mathrm{ml}$ penthiopyrad treatment, the glycerol contents of three strains TZ51S, TZ84S, and TZ55S were significantly decreased compared with the control (Fig. 5B).

Oxalic acid content. The content of oxalic acid was determined by absorbance at $510 \mathrm{~nm}$ of inoculated YEPD treated or untreated
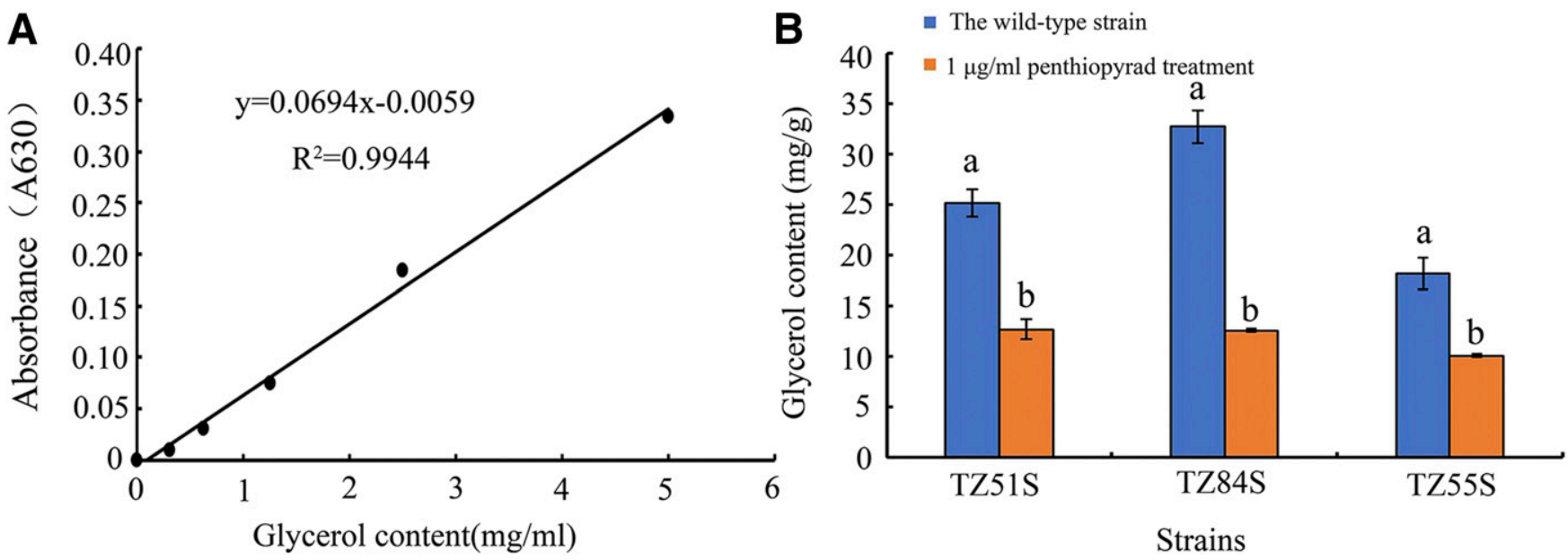

Fig. 5. Standard curve for determination of glycerol content (A) and glycerol content of mycelia of three wild-type Sclerotinia sclerotiorum strains (TZ51S, TZ84S, and TZ55S) with 1 $\mu \mathrm{g} / \mathrm{ml}$ penthiopyrad treatment (B). Bars denote the standard deviation of three experiments. 
with penthiopyrad. The content of oxalic acid was calculated using the standard curves (Fig. 6A). The oxalic acid of S. sclerotiorum strains TZ51S, TZ84S, and TZ55S treated with $1 \mu \mathrm{g} / \mathrm{ml}$ penthiopyrad were significantly lower than the control (Fig. 6B).

EPS content. The content of EPS was determined by absorbance at $490 \mathrm{~nm}$ of inoculated YEPD treated or untreated with penthiopyrad. EPS content was calculated using the standard curves (Fig. 7A). EPS contents of S. sclerotiorum strains TZ51S, TZ84S, and TZ55S treated with $1 \mu \mathrm{g} / \mathrm{ml}$ penthiopyrad were significantly lower than control (Fig. 7A).

Inhibition of mycelial respiration. Treated with 0.5 or $1 \mu \mathrm{g} / \mathrm{ml}$ penthiopyrad, the respiration of mycelia could be strongly inhibited when the mycelia were treated for $2 \mathrm{~h}$. The inhibition rate of respiration in mycelia of S. sclerotiorum strain TZ55S reached about $70 \%$ when treated with $1 \mu \mathrm{g} / \mathrm{ml}$ penthiopyrad (Fig. 8).

Protective and curative activity of penthiopyrad on leaves of rapeseed. Protective and curative activity of penthiopyrad against $S$. sclerotiorum on detached rapeseed leaves were determined. Penthiopyrad exhibited both protective and curative activity on the detached rapeseed leaves. The control efficacy of protective and curative activity increased with increases in penthiopyrad concentration. For protective activity, when the penthiopyrad concentration was 80 and $100 \mu \mathrm{g} / \mathrm{ml}$, the protective effect reached 81.07 and $100 \%$. For curative activity assay, when the penthiopyrad concentration was $100 \mu \mathrm{g} / \mathrm{ml}$, the protective effect reached to $72.34 \%$ (Table 2, Fig. 9).

\section{Discussion}

The filamentous ascomycete Sclerotinia sclerotiorum (Lib.) de Bary is a cosmopolitan plant-pathogenic fungus, which can cause heavy harm to yield and quality of the rapeseed. At present, the application of different fungicides is still the main method for controlling SSR. Penthiopyrad is an SDHI and has excellent efficacy against many different plant diseases (Avenot et al. 2012). In this study, the baseline sensitivity of $S$. sclerotiorum to penthiopyrad was determined by analyzing $\mathrm{EC}_{50}$ values of 119 strains from Jiangsu Province of China. The $\mathrm{EC}_{50}$ values for penthiopyrad ranged from 0.0096 to $0.2606 \mu \mathrm{g} / \mathrm{ml}$, and the mean value was $0.0578( \pm 0.0626) \mu \mathrm{g} / \mathrm{ml}$. The baseline sensitivity curve was unimodal over a sensitive range (Fig. 1B), which indicated that penthiopyrad has a significant effect on mycelial growth of S. sclerotiorum. Baseline sensitivity is essential for subsequent assessment of resistance risk and monitoring propamidine resistance in $S$. sclerotiorum populations in the future. To our knowledge, the $\mathrm{EC}_{50}$ values of $S$. sclerotiorum for penthiopyrad was lower than propamidine, azoxystrobin, iprodione, and trifloxystrobin (Di et al. 2016; Duan et al. 2012; Liu et al. 2009; Wang et al. 2017), but higher than boscalid, fluazinam, fludioxonil, and benzothiostrobin (Kuang et al. 2011; Liu et al. 2009; Wang et al. 2016; C. Y. Xu et al. 2014). In addition, after treatment with $1 \mu \mathrm{g} /$ $\mathrm{ml}$ penthiopyrad, mycelia of $S$. sclerotiorum isolates TZ51S, TZ84S, and TZ55S showed increased apical branching compared with the control (Fig. 2). In the present research, we found that the intracellular plasma leakage increased significantly after penthiopyrad
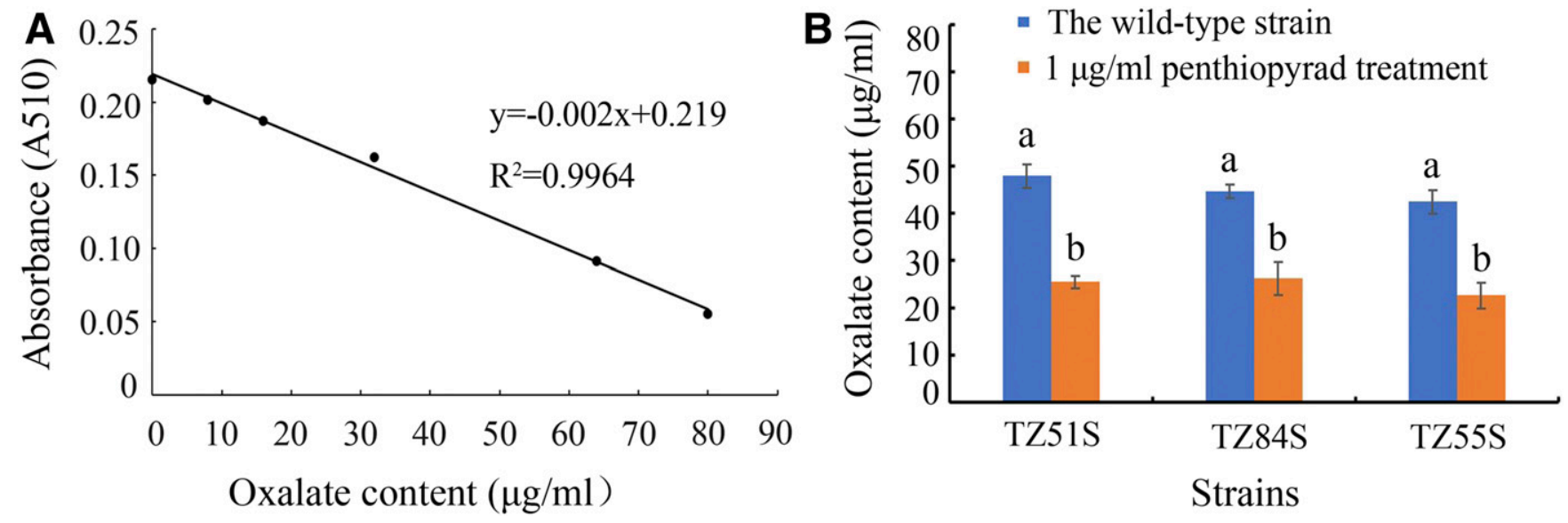

Fig. 6. Standard curve for determination of oxalic acid content (A) and oxalic acid content of mycelia of three wild-type Sclerotinia sclerotiorum strains (TZ51S, TZ84S, and TZ55S) with $1 \mathrm{\mu g} / \mathrm{ml}$ penthiopyrad treatment (B). Bars denote the standard deviation of three experiments.
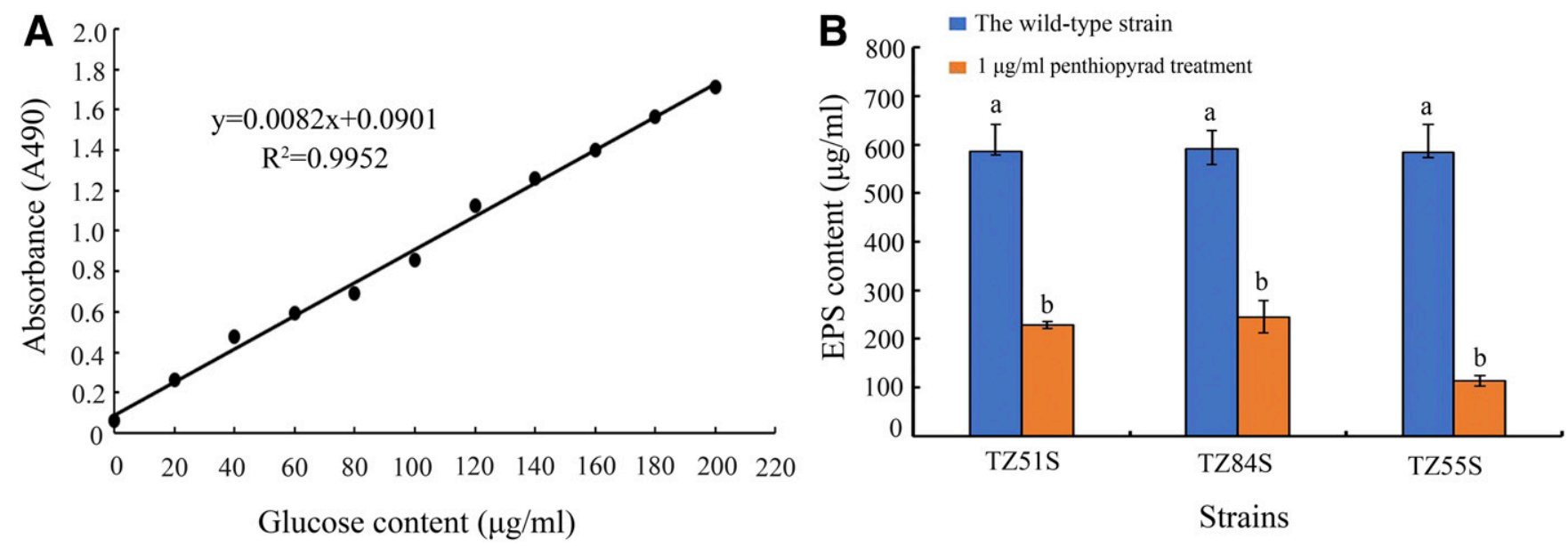

Fig. 7. Standard curve for determination of EPS content (A) and EPS content of mycelia of three wild-type Sclerotinia sclerotiorum strains (TZ51S, TZ84S, and TZ55S) with $1 \mu \mathrm{g} / \mathrm{ml}$ penthiopyrad treatment (B). Bars denote the standard deviation of three experiments. 
treatment, which may be correlated with changes in mycelia morphology. Those data suggested that the fungicide penthiopyrad could damage the membrane structure and cause mycelial electrolyte leakage. Increased cell membrane permeability after penthiopyrad treatment was also correlated with changes in hyphal morphology. In summary, these results could provide new reference data for controlling SSR and penthiopyrad might be applied to manage the resistance to aforementioned fungicides in the field.

Sclerotia, as the primary survival structures of S. sclerotiorum, could initiate another disease cycle when circumstances are suitable

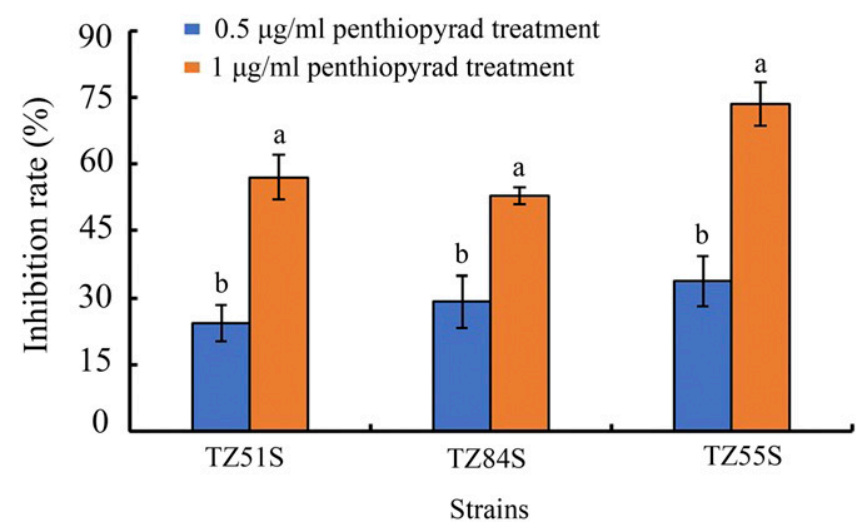

Fig. 8. Inhibition rate of oxygen consumption in mycelia of three wild-type Sclerotinia sclerotiorum strains (TZ51S, TZ84S, and TZ55S) after $0.5 \mu \mathrm{g} / \mathrm{ml}$ or $1 \mu \mathrm{g} / \mathrm{ml}$ penthiopyrad treatment in $2 \mathrm{~h}$. Bars denote the standard deviation of three experiments.
(Duan et al. 2012). In the present study, the number and dry weight of sclerotia decreased significantly after penthiopyrad treatment (Fig. 3). This result suggests that penthiopyrad could not only inhibit the hyphal growth but may also affect the production of sclerotia.

In $S$. sclerotiorum, OA is a vital virulence factor; oxalate-deficient mutants are nonpathogenic on host plants (Godoy et al. 1990). But beyond that, oxalate-deficient mutants of $S$. sclerotiorum fail to develop sclerotia (Godoy et al. 1990). Oxalate secretion might increase Sclerotinia virulence in several ways (Duan et al. 2013). We found that the contents of OA and EPS decreased significantly after penthiopyrad treatment, which indicated that the fungicide could inhibit the development of OA and EPS. This indicates that penthiopyrad might lead to a decrease of oxalate secretion and damage of the infection pad in S. sclerotiorum, and which may be attributed to protective and curative effects against $S$. sclerotiorum on leaves of rapeseed.

Penthiopyrad is a novel fungicide belonging to the SDHI fungicide group, and it has shown excellent efficacy against many different plant diseases, but the biological activity of penthiopyrad is unknown. Our results indicated that penthiopyrad had both protective and curative effects on leaves of rapeseed, and that the protective effect was better than the curative effect. Protective and curative activity of penthiopyrad increased with the increase of penthiopyrad concentration. But the control efficacy of penthiopyrad against SSR in the field is unknown, which should be further studied.

In summary, further research is required to study on the action site of penthiopyrad on S. sclerotiorum. Penthiopyrad exhibited high physiological and biochemical activity against $S$. sclerotiorum in vitro. The present research indicates that penthiopyrad may present good opportunities to control SSR by decreasing contents of EPS and OA. As far as we know, penthiopyrad could interference with fungal respiration in complex II of the cytochrome system and inhibit

Table 2. Protective and curative activity of penthiopyrad against Sclerotinia sclerotiorum on leaves of rapeseed

\begin{tabular}{|c|c|c|c|c|}
\hline \multirow[b]{2}{*}{ Penthiopyrad $(\mu \mathrm{g} / \mathrm{ml})$} & \multicolumn{2}{|c|}{ Protective activity in leaves } & \multicolumn{2}{|c|}{ Curative activity in leaves } \\
\hline & Lesion diameter $(\mathrm{cm})$ & Control efficacy $(\%)$ & Lesion diameter $(\mathrm{cm})$ & Control efficacy $(\%)$ \\
\hline 0 & $3.17 \mathrm{a}^{\mathrm{z}}$ & & $3.39 \mathrm{a}$ & \\
\hline 12.5 & $2.07 \mathrm{~b}$ & 34.7 & $2.4 \mathrm{~b}$ & 29.3 \\
\hline 25 & $1.44 \mathrm{c}$ & 54.57 & $1.87 \mathrm{c}$ & 47.79 \\
\hline 50 & $0.66 \mathrm{~d}$ & 79.18 & $1.68 \mathrm{~d}$ & 60.07 \\
\hline 80 & $0.6 \mathrm{~d}$ & 81.07 & $1.34 \mathrm{e}$ & 69.72 \\
\hline 100 & $0 \mathrm{e}$ & 100 & $1.03 \mathrm{e}$ & 72.34 \\
\hline
\end{tabular}

${ }^{\mathrm{z}}$ Means in a column followed by the same letter were not significantly different according to Fisher's least significant difference (LSD) test $(P=0.05)$.

A
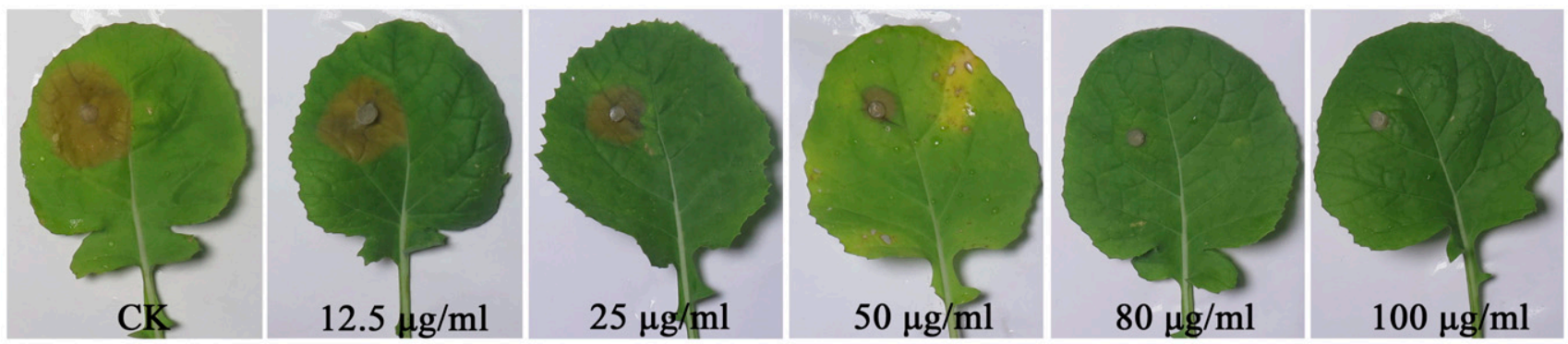

B
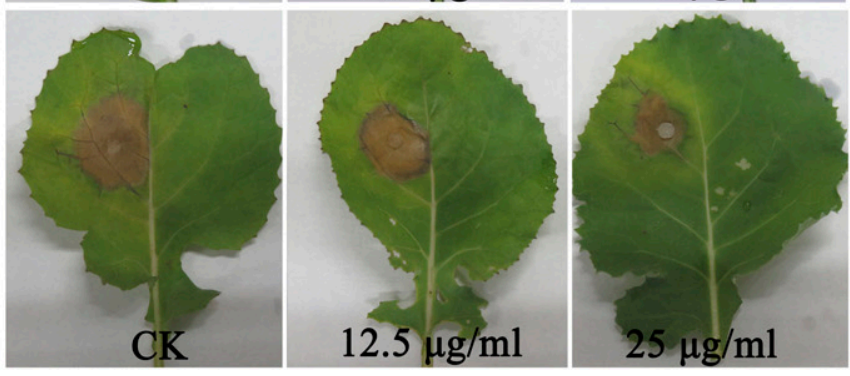
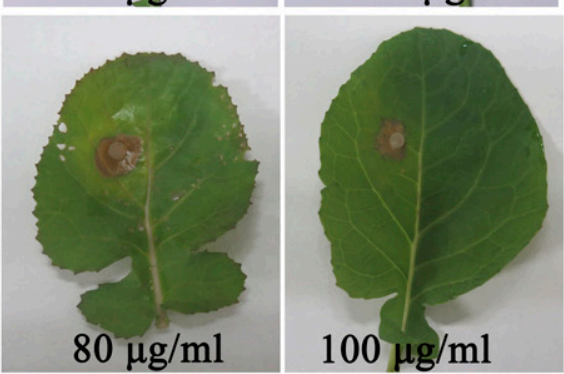

Fig. 9. Protective and curative activity of penthiopyrad against Sclerotinia sclerotiorum on leaves of rapeseed. A, Protective activity. B, Curative activity. 
fungal respiration. Our study suggested that penthiopyrad is more effective against $S$. sclerotiorum on leaves of rapeseed. Penthiopyrad has not been registered for controlling SSR, which may present a good alternative fungicide to control $S$. sclerotiorum.

\section{Literature Cited}

Aghajani, M. A., Safaie, N., and Alizadeh, A. 2010. Disease progress curves of sclerotinia stem rot of canola epidemics in Golestan province. Iran. J. Agric. Sci. Tech. 12:471-478.

Avenot, H. F., and Michailides, T. J. 2010. Progress in understanding molecular mechanisms and evolution of resistance to succinate dehydrogenase inhibiting (SDHI) fungicides in phytopathogenic fungi. Crop Prot. 29:643-651.

Avenot, H. F., Thomas, A., Gitaitis, R. D., Langston, D. B., and Stevenson, K. L. 2012. Molecular characterization of boscalid- and penthiopyrad-resistant isolates of Didymella bryoniae and assessment of their sensitivity to fluopyram. Pest Manag. Sci. 68:645-651.

Bolton, M. D., Thomma, B. P. H. J., and Nelson, B. D. 2006. Sclerotinia sclerotiorum (lib.) de Bary: biology and molecular traits of a cosmopolitan pathogen. Mol. Plant Pathol. 7:1-16.

Chen, Y., Jin, L. H., and Zhou, M. G. 2009. Effect of azoxystrobin on oxygen consumption and cyt $b$ gene expression of Colletotrichum capsici from chilli fruits. Agric. Sci. China 8:628-631.

Culbreath, A. K., Brenneman, T. B., Kemerait, R. C., and Hammes, G. G. 2009. Effect of the new pyrazole carboxamide fungicide penthiopyrad on late leaf spot and stem rot of peanut. Pest Manag. Sci. 65:66-73.

Derbyshire, M., Denton-Giles, M., Hegedus, D., Seifbarghi, S., Rollins, J., Kan, J. V., Seidl, M. F., Faino, L., Mbengue, M., Navaud, O., Raffaele, S., Hammond-Kosack, K., Heard, S., and Oliver, R. 2017. The complete genome sequence of the phytopathogenic fugus Sclerotinia sclerotiorum reveals insights into the genome architecture of broad host range pathogens. Genome Biol. Evol. 9:593-618.

Derbyshire, M. C., and Denton-Giles, M. 2016. The control of sclerotinia stem rot on oilseed rape (Brassica napus): current practices and future opportunities. Plant Pathol. 65:859-877.

Di, Y. L., Zhu, Z. Q., Lu, X. M., and Zhu, F. X. 2016. Baseline sensitivity and efficacy of trifloxystrobin against Sclerotinia sclerotiorum. Crop Prot. 87: 31-36.

Duan, L. Z., Wang, J. F., and Zhao, J. R. 2007. Study on the determining conditions of oxalate content in spinach with coloration method.J. Anhui. Agric. Sci. (Melb.) 35:632-633.

Duan, Y. B., Ge, C. Y., Liu, S. M., Chen, C. J., and Zhou, M. G. 2013. Effect of phenylpyrrole fungicide fludioxonil on morphological and physiological characteristics of Sclerotinia sclerotiorum. Pestic. Biochem. Physiol. 106: 61-67.

Duan, Y. B., Liu, S. M., Ge, C. Y., Feng, X. J., Chen, C. J., and Zhou, M. G. 2012. In vitro inhibition of Sclerotinia sclerotiorum by mixtures of azoxystrobin, SHAM, and thiram. Pestic. Biochem. Physiol. 103:101-107.

DuBois, M., Gilles, K. A., Hamilton, J. K., Rebers, P. A., and Smith, F. 1956. Calorimetric method for determination of sugars and related substances. Anal. Chem. 28:350-356.

Godoy, G., Steadman, J. R., Dickman, M. B., and Dam, R. 1990. Use of mutants to demonstrate the role of oxalic acid in pathogenicity of Sclerotinia sclerotiorum on Phaseolus vulgaris. Physiol. Mol. Plant Pathol. 37:179-191.

Guyon, K., Balagué, C., Roby, D., and Raffaele, S. 2014. Secretome analysis reveals effector candidates associated with broad host range necrotrophy in the fungal plant pathogen Sclerotinia sclerotiorum. BMC Genomics 15:336.

Kuang, J., Hou, Y. P., Wang, J. X., and Zhou, M. G. 2011. Sensitivity of Sclerotinia sclerotiorum to fludioxonil: in vitro determination of baseline sensitivity and resistance risk. Crop Prot. 30:876-882.

Kurt, S., Gunes, U., and Soylu, E. M. 2011. In vitro and in vivo antifungal activity of synthetic pure isothiocyanates against Sclerotinia sclerotiorum. Pest Manag. Sci. 67:869-875

Li, J. L., Kang, T. H., Talab, K. M. A., Zhu, F. X., and Li, J. H. 2017. Molecular and biochemical characterization of dimethachlone resistant isolates of Sclerotinia sclerotiorum. Pestic. Biochem. Physiol. 138:15-21.
Liu, S. M., Fu, L. Y., Hai, F., Jiang, J., Che, Z. P., Tian, Y., and Chen, G. 2018a. Sensitivity to boscalid in field isolates of Sclerotinia sclerotiorum from rapeseed in Henan Province, China. J. Phytopathol. 166:227-232.

Liu, S. M., Hai, F., and Jiang, J. 2017. Sensitivity to fludioxonil of Botrytis cinerea isolates from tomato in Henan Province of China and characterizations of fludioxonil-resistant mutants. J. Phytopathol. 165:98-104.

Liu, S. M., Zhang, Y., Che, Z. P., Tian, Y., and Chen, G. Q. 2018b. Carbendazim resistance and dimethachlone sensitivity of field isolates of Sclerotinia sclerotiorum from oilseed rape in Henan Province, China. J. Phytopathol. 166:701-708.

Liu, X., Yin, Y. N., Yan, L. Y., Michailides, T. J., and Ma, Z. H. 2009. Sensitivity to iprodione and boscalid of Sclerotinia sclerotiorum isolates collected from rapeseed in China. Pestic. Biochem. Physiol. 95:106-112.

Proffer, T. J., Lizotte, E., Rothwell, N. L., and Sundin, G. W. 2013. Evaluation of dodine, fluopyram and penthiopyrad for the management of leaf spot and powdery mildew of tart cherry, and fungicide sensitivity screening of Michigan populations of Blumeriella jaapii. Pest Manag. Sci. 69:747-754.

Rao, P., and Pattabiraman, T. N. 1989. Reevaluation of the phenol-sulfuric acid reaction for the estimation of hexoses and pentoses. Anal. Biochem. 181:18-22.

Russell, P. E. 2004. Sensitivity baselines in fungicide resistance research and management. FRAC Monograph No. 3. Brussels, Belgium. https:// www.frac.info/docs/default-source/publications/monographs/monograph-3.pdf.

Shirane, N., Masuko, M., and Takeda, R. 1995. Effects of SSF-126, a novel alkoxyiminoacetamide blastidde, on mycelial growth and oxygen consumption of Pyricularia oryzae. Plant Pathol. 44:636-640.

Stammler, G., Benzinger, G., and Speakman, J. A. 2007. Rapid and reliable method for monitoring the sensitivity of Sclerotinia sclerotiorum to boscalid. J. Phytopathol. 155:746-748.

Steadman, J. R. 1979. Control of plant diseases caused by Sclerotinia species. Phytopathology 69:904-907.

Wang, Y., Duan, Y. B., and Zhou, M. G. 2016. Baseline sensitivity and efficacy of fluazinam in controlling Sclerotinia stem rot of rapeseed. Eur. J. Plant Pathol. 144:337-343.

Wang, Y., Sun, Y., Zhang, Y., Zhang, Y. X., Han, L. R., Zhang, X., and Feng, J. T. 2017. Sensitivity and biochemical characteristics of Sclerotinia sclerotiorum to propamidine. Pestic. Biochem. Physiol. 135:82-88.

Xu, C. Y., Hou, Y. P., Wang, J. X., Yang, G. F., Liang, X. Y., and Zhou, M. G. 2014. Activity of a novel strobilurin fungicide benzothiostrobin against Sclerotinia sclerotiorum. Pestic. Biochem. Physiol. 115:32-38.

Xu, D. F., Li, X. L., Pan, Y. M., Dai, Y. L., Li, P., Chen, F. X., Zhang, H. J., Guo, M., and Gao, Z. M. 2014. Genetic diversity and pathogenicity differentiation of Sclerotinia sclerotiorum on rapeseed (Brassica napus L.) in Anhui Province, China. Genet. Mol. Res. 13:10704-10713.

Xu, T., Wang, Y. T., Liang, W. S., Yao, F., Li, Y. H., Li, D. R., Wang, H., and Wang, Z. Y. 2013. Involvement of alternative oxidase in the regulation of sensitivity of Sclerotinia sclerotiorum to the fungicides azoxystrobin and procymidone. J. Microbiol. 51:352-358.

Yan, J., and Qiu, T. Q. 2004. Determination of glycerol by cupric glycerinate colorimetry. China Oils Fats. 29:40-43.

Yanase, Y., Yoshikawa, Y., Kishi, J., and Katsuta, H. 2007. The History of Complex II Inhibitors and the Discovery of Penthiopyrad. Pages 295-303 in: Pesticide Chemistry: Crop Protection. H. Ohkawa, H. Miyagawa, and P. W. Lee, eds. Wiley-VCH, Weinheim, Germany.

Zhang, X. L., Sun, X. M., Zhang, G. F., Yi, H. J., and Qiang, Y. 2003. Preliminary report on the monitoring of the resistance of Sclerotinia sclerotiorum to carbendazim and its integrated management. Pestic. Sci. Admin. 24:18-22.

Zhao, J., Peltier, A. J., Meng, J., Osborne, T. C., and Grau, C. R. 2004. Evaluation of sclerotinia stem rot resistance in oilseed Brassica napus using a petiole inoculation technique under greenhouse conditions. Plant Dis. 88:1033-1039.

Zhou, F., Zhang, X. L., Li, J. L., and Zhu, F. X. 2014a. Dimethachlon resistance in Sclerotinia sclerotiorum in China. Plant Dis. 98:1221-1226.

Zhou, F., Zhu, F. X., Zhang, X. L., and Zhang, A. S. 2014b. First report of dimethachlon resistance in field isolates of Sclerotinia sclerotiorum on oilseed rape in Shaanxi Province of northwestern China. Plant Dis. 98:568.

Zhu, Z. Q., Zhou, F., Li, J. L., Zhu, F. X., and Ma, H. J. 2016. Carbendazim resistance in field isolates of Sclerotinia sclerotiorum in China and its management. Crop Prot. 81:115-121. 